\title{
PENERAPAN DATA MINING METODE DECISION TREE UNTUK MENGUKUR PENGUASAAN BAHASA INGGRIS MARITIM (STUDI KASUS DI UNIVERSITAS MARITIM AMNI)
}

\author{
Endah Fauziningrum \\ Universitas Maritim AMNI \\ e-mail : endah.amni@gmail.com \\ Encis Indah Suryaningsih, S.T., M. Pd \\ Universitas Maritim AMNI \\ e-mail : encis.indah@gmail.com
}

\begin{abstract}
ABSTRAK
Bahasa Inggris Maritim merupakan suatu pengetahuan dan kemampuan yang harus dimiliki oleh taruna dengan baik. Cara mengetahui sampai dimana kemampuan Bahasa Inggris Maritim yang dimiliki yaitu dengan adanya nilai. Penilaian merupakan serangkaian kegiatan untuk memeroleh informasi atau data mengenai proses dan hasil belajar siswa. Nilai-nilai ini dapat dioptimalkan untuk memprediksi hasil pembelajaran mendatang menggunakan Decision Tree. Decision tree atau pohon keputusan merupakan salah satu cara dalam data mining untuk memprediksi masa depan dengan membangun klasifikasi atau regresi model dalam bentuk struktur pohon. Tujuan dari penelitian ini adalah memprediksi kemampuan bahasa Inggris taruna di masa mendatang dengan menggunakan 4 atribut yaitu berbicara (speaking), mendengarkan (listening), membaca (reading), dan menulis (writing). Hasil dari penelitian ini menyatakan bahwa untuk Mata Kuliah Bahasa Inggris Maritim, kemampuan berbicara (speaking) mempunyai dampak yang besar terhadap atribut yang lain. Sehingga perlu diberikan perlakuan khusus terhadap taruna yang tidak lulus. Dan perlu peningkatan pembelajaran untuk reading, writing terutama listening.
\end{abstract}

Kata kunci: Penilaian, Prediksi, Bahasa Inggris Maritim, Data Mining, Decision Tree

\begin{abstract}
Maritime English is a knowledge and an ability that all cadets must mastered. The way to find out to what extent Maritime English skills are mastered is through assessment. Assessment is a series of activities to obtain information or data about the process and student learning outcomes. These values can be optimized to predict future learning outcomes using Decision Tree. Decision tree is one way in data mining to predict the future by building a classification or regression model in the form of a tree structure. The purpose of this study is to predict the cadets' Maritime English language skills in the future by using 4 attributes. They are reading, writing, speaking, and listening. The result of this research indicates that for Maritime English, speaking skills have a large impact on other attributes. So, it is necessary to give special treatment to cadets who do not pass. And it is necessary to improve learning for reading, writing, especially listening.
\end{abstract}

Keywords: Assessment, Prediction, Maritime English, Data Mining, Decision Tree 


\section{Pendahuluan}

Pembelajaran merupakan suatu cara agar seseorang memperoleh pengetahuan dan keterampilan. Salah satu cara yang dapat dilakukan untuk mengetahui hasil yang dicapai oleh pendidik dalam proses pembelajaran adalah melalui penilaian. Afrida (2016:138) mengemukakan bahwa penilaian capaian pembelajaran merupakan bagian dari evaluasi yang sangat penting dalam proses pembelajaran atau pendidikan. Pendapat tersebut sejalan dengan Nurgiyantoro (2011:22) yang menyatakan bahwa penilaian merupakan proses sistematis dalam pengumpulan, analisis, dan penafsiran informasi untuk membuat keputusan. Sedangkan untuk Bahasa Inggris, Panjaitan (2010:316) menyatakan penilaian dalam mata pelajaran Bahasa Ingggris adalah suatu kegiatan yang mengukur penguasaan bahasa inggris peserta didik, agar memperoleh informasi sejaug mana indikatoindikator keberhasilan yang telah dirumuskan telah nampak pada perilaku berbahasa inggris peserta didik. Sehingga dapat ditarik kesimpilan bahwa penilaian dilakukan dengan cara menganalisis dan menafsirkan data hasil pengukuran capaian kompetensi siswa yang dilakukan secara sistematis dan berkesinambungan sehingga menjadi informasi yang bermakna dalam pengambilan keputusan. Penilaian merupakan sub sistem yang sangat di butuhkan dalam setiap sistem pendidikan, karena penilaian dapat mencerminkan seberapa jauh perkembangan atau kemajuan hasil pendidikan. Kegiatan penilaian merupakan salah satu kegiatan utama yang harus dilakukan dalam suatu aktifitas pendidikan dan pembelajaran. Dari hasil penilaian, kita bisa mengetahui perkembangan hasil belajar, intelegensi, bakat khusus, minat, hubungan sosial, sikap, dan kepribadian siswa atau peserta didik serta keberhasilan sebuah program.

Pada Program Studi Diploma Tiga Nautika Universitas Maritim AMNI, Mata Kuliah Bahasa Inggris disebut dengan Bahasa Inggris Maritim atau Maritime English. Bahasa Inggris Maritim/Maritime English pada IMO Model Course 3.17 (2015:11) for Maritime English menyatakan bahwa Maritime English is a controlled natural language, designed to facilitate communication between ships whose captains' native tongues differ. Dengan penjelasan tersebut dapat ditarik kesimpulan bahwa Bahasa Inggris Maritim adalah sebuah bahasa yang memang dirancang untuk percakapan atau komunikasi di atas kapal baik antar kapal, antara kru kapal maupun pihak petugas pelabuhan. Berdasarkan tuntutan internasional, maka Program Studi D3 Nautika Universitas Maritim AMNI menggunakan silabus Bahasa Inggris Maritim berdasarkan Standards of Training Certification and Watchkeeping (STCW) Amendment 2010 yang terdeskripsikan dalam International Maritime Organization Model Course (IMO MC) 3.17 for Maritime English.

Dalam penilaiannya, Bahasa Inggris Maritim menggunakan empat kompetensi dasar, yaitu: kompetensi berbicara (speaking), kompetensi mendengarkan (listening), kompetensi membaca (reading), dan kompetensi menulis (writing). Menurut Ardiyansah (2019:25) the assessment should be given by the teachers based on the objectives skill itself, maka Dosen Mata Kuliah Bahasa Inggris Maritim menetapkan passing grade dengan nilai 60. Hal ini berdasarkan pada passing grade yang telah ditetapkan dalam Buku Panduan Akademik Universitas Maritim AMNI.

Universitas Maritim AMNI mempunyai banyak data hasil penilaian Bahasa Inggris Maritim, akan tetapi data tersebut belum diolah secara maksimal. Padahal apabila data yang sudah ada diolah dengan maksimal, dapat untuk memprediksi hasil nilai taruna di masa mendatang. Untuk dapat membuat prediksi, dapat menggunakan data mining dengan algoritma decision tree. Data mining merupakan suatu kegiatan yang meliputi pengumpulan, pemakaian data historis untuk menemukan keteraturan, pola atau hubungan dalam set data berukuran besar (Swastina,2013). Data Mining sendiri memiliki beberapa teknik salah satunya klasifikasi. Klasifikasi merupakan suatu proses yang menemukan properti-properti yang sama pada sebuah himpunan obyek di dalam sebuah basis data dan mengklasifikasikannya ke dalam kelas-kelas yang berbeda menurut model klasifikasi yang ditetapkan (Selvia, dkk, 2014). Proses yang digunakan dalam data mining menggunakan metode statistika, ilmu matematika, machine learning dan teknologi artificial intelligence atau kecerdasan buatan. Teknik 
dalam data mining ada berbagai macam antara lain untuk prediksi, segmentasi, analisis, dan decision tree.

Decision tree adalah struktur flowchart yang mempunyai tree (pohon), dimana setiap simpul internal menandakan suatu tes atribut, setiap cabang merepresentasikan hasil tes, dan simpul daun merepresentasikan kelas atau distribusi kelas (Wahyudin, 2009). Tahapan-tahapan dalam Decision tree menurut Kusri Ridwan, M., Suyono, H., dan Sarosa, M (2013) dalam Penerapan Data Mining Untuk Evaluasi Kinerja Akademik Mahasiswa Menggunakan Algoritma Naive Bayes Classifier, tahap-tahap Data Mining Decision Tree ada 7, yaitu:

a. Pembersihan data (data cleaning), Pembersihan data merupakan proses menghilangkan noise dan data yang tidak konsisten atau data tidak relevan. Integrasi data (data integration). Pada umumnya data yang diperoleh, baik dari database memiliki isian-isian yang tidak sempurna seperti data yang hilang, data yang tidak valid atau juga hanya sekedar salah ketik, selanjutnya Data-data yang tidak relevan itu juga lebih baik dibuang, hal ini juga diartikan Pembersihan data juga akan mempengaruhi performasi dari teknik data mining karena data yang ditangani akan berkurang jumlah dan kompleksitasnya.

b. Integrasi data merupakan penggabungan data dari berbagai database ke dalam satu database baru. Integrasi data perlu dilakukan secara cermat karena kesalahan pada integrasi data bisa menghasilkan hasil yang menyimpang dan bahkan menyesatkan pengambilan aksi nantinya. Hal ini dapat di contohkan bila integrasi data berdasarkan jenis produk ternyata menggabungkan produk dari kategori yang berbeda maka akan didapatkan korelasi antar produk yang sebenarnya tidak ada.

c. Seleksi Data (Data Selection), Tahapan selanjutnya dalam adalah seleksi. Proses seleksi merupakan proses penyeleksian data. Data yang diseleksi akan ditransformasikan ke format yang sesuai untuk analisis data. Seleksi data menggunakan beberapa kriteria. Data hasil seleksi kemudian akan disimpan di suatu berkas terpisah yang kemudian akan diolah atau dilakukan proses data mining, data yang ada pada database sering kali tidak semuanya dipakai, oleh karena itu hanya data yang sesuai untuk dianalisis yang akan diambil dari database. Sebagai contoh, sebuah kasus yang meneliti faktor kecenderungan orang membeli dalam kasus market basket analysis, tidak perlu mengambil nama pelanggan, cukup dengan id pelanggan saja.

d. Transformasi data (Data Transformation), data diubah atau digabung ke dalam format yang sesuai untuk diproses dalam data mining. Proses transformasi atau coding merupakan proses transformasi data ke dalam format tertentu sehingga nantinya data dapat digunakan dan ditelusuri. Sebagai contoh beberapa metode standar seperti analisis asosiasi dan clustering hanya bisa menerima input data kategorikal. Karenanya data berupa angka numerik yang berlanjut perlu dibagi-bagi menjadi beberapa interval. Proses ini sering disebut transformasi data.

e. Proses mining merupakan suatu proses utama saat metode diterapkan untuk menemukan pengetahuan berharga dan tersembunyi dari data.

f. Evaluasi pola (pattern evaluation), untuk mengidentifikasi pola-pola menarik ke dalam knowledge-based yang ditemukan. Dalam tahap ini hasilnya berupa pola-pola yang khas maupun model prediksi dievaluasi untuk menilai apakah hipotesa yang ada memang tercapai, Setelah menemukan pola dan data menarik, selanjutnya adalah menampilkan data tersebut ke dalam bentuk yang mudah dipahami oleh pengguna atau pihak yang berkepentingan. Jadi pola yang ditemukan nanti akan diperiksa dan dicek apakah bertentangan dengan hipotesis sebelumnya ataukah tidak. Intinya data sudah bisa dibaca dan tentunya akan bermanfaat bagi pihak yang berkepentingan.

g. Presentasi pengetahuan (knowledge presentation), merupakan visualisasi dan penyajian pengetahuan mengenai metode yang digunakan untuk memperoleh pengetahuan yang diperoleh pengguna. Tahap terakhir adalah bagaimana memformulasikan keputusan atau aksi dari hasil analisis yang didapat. Karena presentasi dalam bentuk pengetahuan yang bisa dipahami semua orang adalah satu tahapan yang diperlukan.Dalam presentasi ini, visualisasi juga bisa membantu mengkomunikasikan hasil data mining. 
Keunggulan penggunaan Decision Tree untuk memprediksi kemampuan berbahasa Inggris Maritim diperkuat dengan penelitian yang menggunakan aplikasi sistem data mining decision tree, antara lain: Fricles Ariwisanto Sianturi (2018) dalam jurnalnya yang berjudul Analisa Decision Tree Dalam Pengolahan Data Siswa menyatakan bahwa: 1) Perilaku sangat berpengaruh besar didalam menentukan nilai siswa dan hasil nilai yang akan diperolah seorang siswa, maka pihak sekolah harus lebih meningkatkan disiplin dan peraturan didalam sekolah untuk kedepannya. 2) Nilai harian sangat berdampak besar terhadap nilai Ujian Nasional, karena dengan nilai harian yang baik, pasti akan memcerminkan kesiapan seorang siswa untuk mengikuti Ujian Nasional, maka diharapkan pihak sekolah membuat Ekstrakulikuler atau Les tambahan. Sedangkan, Putu Gede Surya Cipta Nugraha dkk (2016) dalam penelitian yang berjudul Penerapan Metode Decision Tree (Data Mining) Untuk Memprediksi Tingkat Kelulusan Siswa SMPN 1 Kintamani menyatakan bahwa dari hasil pengolahan data mining maka didapatlah informasi bahwa siswa yang nilai ujian nasionalnya dibawah standar dan nilai ulangan hariannya rendah atapun menengah mempunyai kemungkinan lebih tinggi untuk mendapatkan hasil tidak lulus dengan kondisi yang terbentuk dari algoritma C.45, yaitu jika nilai ujian nasional memenuhi standar maka hasilnya lulus, jika ujian nasional dibawah standar dan nilai harian rendah maka hasilnya tidak lulus, jika ujian nasional dibawah standar dan nilai harian menengah maka hasilnya tidak lulus dan jika ujian nasional dibawah standar dan nilai harian tinggi maka hasilnya lulus. Keunggulan data mining decision tree dikuatkan oleh Susi Mashlahah (2013) yang menyatakan bahwa akurasi kecocokan pada sistem data mining decision tree mencapai $82,79 \%$ sehingga dapat digunakan untuk memprediksi kelulusan mahasiswa yang belum diketahui.

Dengan pentingnya penguasaan Bahasa Inggris Maritim dalam karir taruna yang sudah lulus, sehingga menguasai Bahasa Inggris Maritim dengan baik menjadi peluang untuk dapat bekerja di perusahaan di luar negeri akan sangat terbuka. Hal ini, tentu saja berpengaruh terhadap pendapatan yang akan mereka dapatkan jika dibandingkan dengan bekerja di perusahaan dalam negeri. Untuk itu, Universitas Maritim AMNI perlu untuk membuat prediksi akan kemampuan Bahasa Inggris Maritim. Hasil dari analisis dan implementasi, nantinya akan diperoleh keputusan yang akurat dalam memprediksi kemampuan taruna dalam penguasaan Bahasa Inggris Maritim, yaitu taruna yang lulus dan tidak lulus.

Diharapkan dengan menggunakan Decision Tree yaitu dengan menggunakan 4 (empat) atribut penunjang yaitu kemampuan berbicara (speaking), mendengarkan (listening), membaca (reading), dan menulis (writing) dapat memprediksi kemampuan Bahasa Inggris Maritim taruna di masa mendatang.

\section{Metodologi Penelitian}

Teknik pengumpulan data menurut Sugiyono, (2014) adalah merupakan langkah yang paling strategis dalam penelitian, karena tujuan utama dari penelitian adalah mendapatkan data. Pada penelitian ini akan menggunakan Riset Perpustakaan (Library Research) dan Riset lapangan (Field Research) yang menggunakan teknik observasi dan data primer. Observasi yaitu metode pengumpulan data yang menggunakan pengamatan secara langsung maupun tidak langsung (Riyanto,2010). Sedangkan data primer (primary data) adalah sumber data dalam pemberian informasi dilakukan secara langsung pada pengumpulan penelitian (Sugiyono, 2014). Road map atau alur penelitian ini terjabarkan dalam Gambar 1. Diagram Alir Penelitian, sebagai berikut:

\section{Diagram Alir}

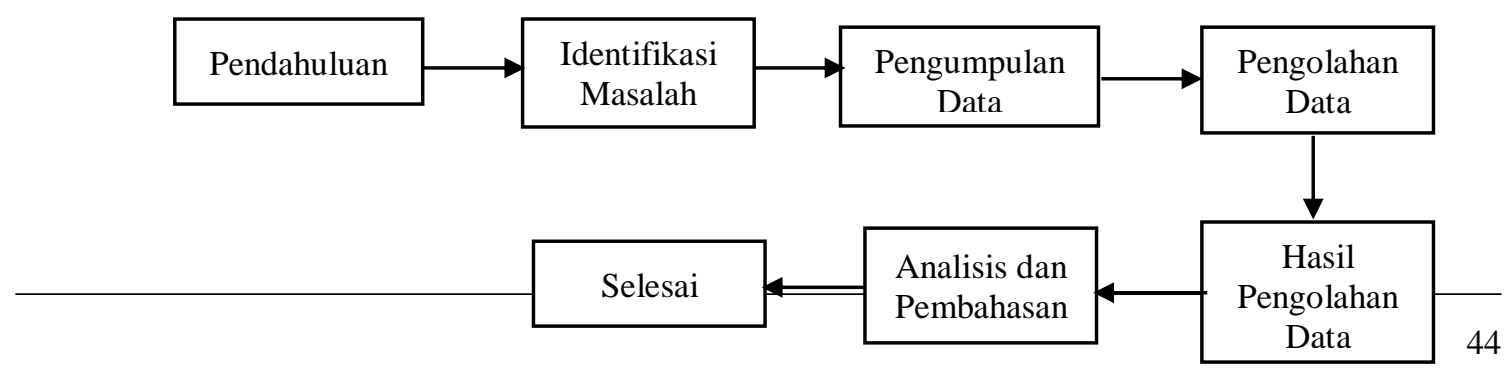


Gambar 1. Diagram Alir Penelitian

(Sumber : Data Sekunder Penelitian)

Penelitian ini diawali dengan:

a. Pendahuluan,yang merumuskan latar belakng, rumusan masalah dan tujuan dari penelitaian sebagai upaya untuk mempersiapkan proposal penelitian.

b. Kemudian dilanjutkan dengan mengidentifikasi masalah yang terjadi dilapangan. Dalam penelitian ini adalah prediksi penguasaan 4 (empat) kemampuan berbahasa yaitu membaca (reading), menulis (writing), berbicara (speaking), dan mendengarkan (listening) dalam Bahasa Inggris Maritim.

c. Dilanjutkan dengan proses pengumpulan data. Untuk memperoleh data yang diperlukan, maka penulis menggunakan beberapa teknik pengumpulan data yaitu: a. Riset Perpustakaan (Library Research), yaitu penelitian yang dilakukan dengan cara pengumpulan data dengan membaca literatur untuk mencari dan mengetahui teori yang berhubungan dengan pokok permasalahan yang sedang diteliti. b. Riset lapangan (Field Research), yaitu penelitian yang dilakukan dengan cara terjun langsung pada objek yang diteliti untuk mendapatkan data-data yang diperlukan baik dengan cara interview maupun observasi, dimana: 1) Observasi yaitu berupa kegiatan pengamatan langsung maupun tidak langsung terhadap objek yang diteliti. 2) Primary data yaitu berupa data yang diperoleh peneliti dari pengumpulan data secara langsung. Data yang diperoleh berupa data historis nilai akademik Taruna semester 1 (satu) Program Studi Diploma Tiga Nautika, Fakultas Kemaritiman, Universitas Maritim AMNI Tahun Akademik 2018/2019.

d. Jika data sudah terkumpul selanjut akan dilakukan pengolahan data dengan menggunakan Data mining dengan teknik decision tree. Algoritma decision tree yang digunakan adalah C4.5. secara umum untuk membangun pohon keputusan adalah sebagai berikut: 1) Pilih atribut sebagai node akar 2) Buat cabang untuk tiap-tiap nilai 3) Bagi kasus dalam cabang 4) Ulangi proses untuk setiap cabang sampai semua kasus pada cabang memiliki kelas yang sama. Penghitungan ini menggunakan Entropy. Entropy digunakan untuk menentukan seberapa informatif sebuah masukan atribut untuk menghasilkan keluaran atribut. Rumus dasar dari Entropy (Larose, 2006) tertera dalam persamaan 1, berikut ini:

$\sum_{i=1}^{\mathrm{n}} 1-p i * \log 2 p i$

Keterangan:

$\mathrm{S}:$ himpunan kasus

A : Fitur

$\mathrm{n}$ : jumlah partisi $\mathrm{S}$

pi : proporsi dari Si terhadap $S$

Untuk memilih atribut sebagai node akar, didasarkan pada nilai Gain tertinggi dari atributatribut yang ada. Untuk menghitung Gain (Larose, 2006) digunakan rumus seperti tertera dalam Persamaan 2 berikut:

Gain $(\mathrm{S}, \mathrm{A})=$ Entropy $(\mathrm{S})-\sum_{i-1}^{n} \frac{s i}{s} * \operatorname{Entropy}(\mathrm{Si})$

Keterangan:

S : Himpunan kasus

A : Atribut

$\mathrm{n}$ : Jumlah partisi atribut A

|Si| : Jumlah kasus pada partisi ke-i 


\section{$|\mathrm{S}|$ : Jumlah kasus dalam $\mathrm{S}$}

e. Hasil pengolahan data merupakan data yang didapat dari perhitungan data atribut-atribut yang telah dipilih yang kemudian dimasukkan pada sistem aplikasi data mining decision tree.

f. Hasil dari pengolahan data kemudian dianalisis dan dibahas sehingga dapat menarik kesimpulan tentang seberapa besar akurasi dari hasil decision tree untuk bisa memprediksi kemampuan bahasa Inggris taruna di masa mendatang.

\section{Hasil dan Pembahasan}

\section{a. Analisa Data}

Pohon keputusan (Decision tree) merupakan flow-chart seperti struktur tree, dimana tiap internal node menunjukkan sebuah test pada sebuah atribut, tiap cabang menunjukkan hasil dari test, dan leaf node menunjukkan class-class atau class distribution. Dari data siswa dapat diperoleh informasi seperti tertera pada tabel-tabel berikut:

Tabel 1. Nilai Speaking

\begin{tabular}{|c|c|}
\hline Nilai Speaking & Jumlah Taruna \\
\hline$<60$ & 1 \\
\hline$=60$ & 0 \\
\hline$>60$ & 183 \\
\hline Total & 184 \\
\hline
\end{tabular}

Sumber : data penelitian

Berdasarkan Tabel 1, maka diketahui bahwa taruna dengan nilai speaking $<60$ adalah sebanyak 1 orang, nilai speaking $=60$ adalah 0 orang sedangkan sisanya $>60$ sebanyak 183 orang.

Tabel 2. Nilai Listening

\begin{tabular}{|c|c|}
\hline Nilai Listening & Jumlah Taruna \\
\hline$<60$ & 46 \\
\hline$=60$ & 20 \\
\hline$>60$ & 118 \\
\hline Total & 184 \\
\hline
\end{tabular}

Sumber : data penelitian

Berdasarkan Tabel 2, maka diketahui bahwa siswa dengan nilai Listening $<60$ adalah sebanyak 46 orang, nilai Listening $=60$ adalah 20 orang, sedangkan sisanya $>60$ sebanyak 118 orang.

Tabel 3. Nilai Reading

\begin{tabular}{|c|c|}
\hline Nilai Reading & Jumlah Taruna \\
\hline$<60$ & 2 \\
\hline$=60$ & 1 \\
\hline$>60$ & 181 \\
\hline Total & 184 \\
\hline
\end{tabular}

Sumber : data penelitian

Berdasarkan Tabel 3, maka diketahui bahwa siswa dengan nilai Reading $<60$ adalah sebanyak 2 orang, nilai Reading $=60$ adalah 1 orang sedangkan sisanya $>60$ sebanyak 181 orang.

Tabel 4. Nilai Writing

\begin{tabular}{|c|c|}
\hline Nilai Writing & Jumlah Taruna \\
\hline$<60$ & 16 \\
\hline
\end{tabular}


Sumber : data penelitian

\begin{tabular}{|c|c|}
\hline$=60$ & 0 \\
\hline$>60$ & 168 \\
\hline Total & 184 \\
\hline
\end{tabular}

Berdasarkan Tabel 4, maka diketahui bahwa siswa dengan nilai Writing $<60$ adalah 16 sebanyak orang, nilai Writing $=60$ adalah 0 orang sedangkan sisanya $>60$ sebanyak 168 orang.

Nilai lulus dalam Mata Kuliah Bahasa Inggris Maritim adalah 60. Hal ini berdasarkan kebijakan Rektor Universitas Maritim AMNI yang terdeskripsikan dalam Buku Panduan Akademik.

\section{b. Hasil Entropy}

Menghitung Entropy berdasarkan jumlah taruna yang lulus, jumlah taruna yang tidak lulus dan dari semua taruna. Kemudian jumlah taruna dibagi berdasarkan atribut nilai speaking, nilai listening, nilai reading dan nilai writing. Setelah itu melakukan Perhitungan Gain dari setiap atribut. Baris total kolom Entropy dapat dihitung dengan Persamaan 1. Sedangkan untuk menghitung Gain dari keseluruhan data menggunakan Persamaan 2. Sehingga node yang dihasilkan dapat dilihat pada tabel 5 berikut:

Tabel 5. Perhitungan Node 1

\begin{tabular}{|c|c|c|c|c|c|c|}
\hline \multirow{2}{*}{ Kompetensi } & \multirow{2}{*}{ Nilai } & \multirow{2}{*}{$\begin{array}{l}\text { Jumlah } \\
\text { Taruna }\end{array}$} & \multicolumn{2}{|c|}{ Status } & \multirow{2}{*}{ Entropy } & \multirow{2}{*}{ Gain } \\
\hline & & & Lulus & Tidak Lulus & & \\
\hline Total & & 184 & 135 & 49 & 0.2517 & \\
\hline \multirow{4}{*}{ Speaking } & & & & & & 0.498 \\
\hline & $<60$ & 1 & 0 & 1 & 0 & \\
\hline & $=60$ & 0 & 0 & 0 & 0 & \\
\hline & $>60$ & 183 & 136 & 47 & 0.2474 & \\
\hline \multirow[t]{4}{*}{ Listening } & & & & & & 0.285 \\
\hline & $<60$ & 46 & 0 & 46 & 0 & \\
\hline & $=60$ & 20 & 19 & 1 & 0.0862 & \\
\hline & $>60$ & 118 & 116 & 2 & 0.0373 & \\
\hline \multirow[t]{4}{*}{ Reading } & & & & & & 0.496 \\
\hline & $<60$ & 2 & 0 & 2 & 0.0000 & \\
\hline & $=60$ & 1 & 1 & 0 & 0.0000 & \\
\hline & $>60$ & 181 & 134 & 47 & 0.2487 & \\
\hline \multirow[t]{4}{*}{ Writing } & & & & & & 0.445 \\
\hline & $<60$ & 16 & 0 & 16 & 0 & \\
\hline & $=60$ & 0 & 0 & 6 & 0 & \\
\hline & $>60$ & 168 & 136 & 32 & 0.2115 & \\
\hline
\end{tabular}

Sumber : hasil olah data penelitian

Menghitung seluruh Entropy : $\sum_{i-1}^{a}-p i * \log _{2} p i$ 


$$
\text { Entropy }(\text { Total })=-\frac{135}{184} * \log _{2}\left(\frac{135}{184}\right)+\left(-\frac{49}{184} * \log _{2}\left(\frac{49}{184}\right)\right)=0,2517
$$

\section{c. Decision Tree}

Dengan hasil tersebut diatas, maka decision tree atau pohon keputusan dapat digambarkan sebagai berikut:

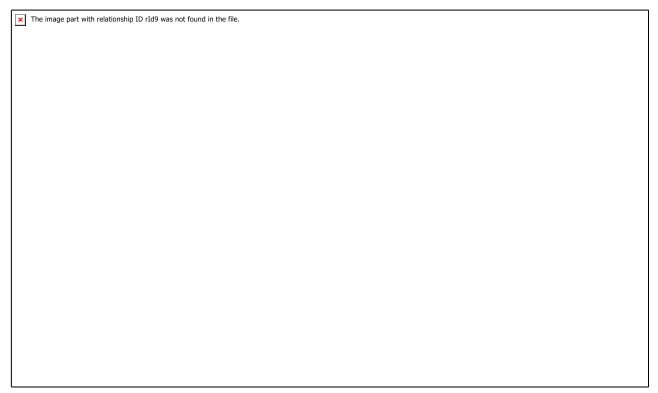

Gambar 2. Decision Tree Speaking

(Sumber : hasil data penelitian)

Node berikutnya dapat dipilih pada bagian yang mempunyai atau memiliki nilai antara Lulus dan T.Lulus, pada node 1 diatas atribut $<60$ sudah memiliki keputusan tidak lulus, dan atribut $=60$ memiliki keputusan lulus sehinga tidak perlu dijelaskan lagi. Pada node 1 untuk atribut $>60$ belum mempunyai keputusan untuk itu diperlukan perhitungan selanjutnya.

\section{d. Hasil Akhir}

Maka, hasil akhir dari perhitungan diatas dapat dilihat pada gambar 3 berikut ini:

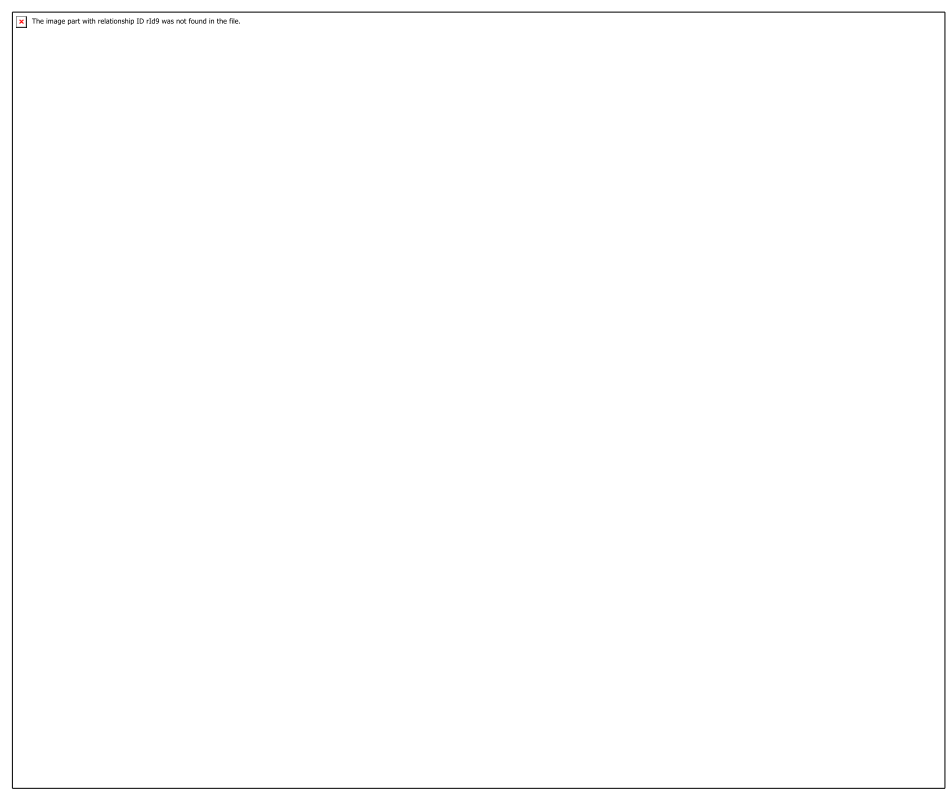

Gambar 3. Hasil dari Algoritma Decision Tree

(Sumber : hasil data penelitian)

Berdasarkan gambar pohon keputusan maka didapat aturan pohon keputusan sebagai berikut :

1) Jika Speaking nilai $<60$ maka tidak lulus 
2) Jika Speaking nilai $=60$ maka lulus

3) Jika Speaking nilai $>60$, nilai reading <60 maka tidak lulus

4) Jika Speaking nilai $>60$, nilai reading $=60$ maka lulus

5) Jika Speaking nilai $>60$, nilai reading $>60$, nilai writing $<60$ maka tidak lulus

6) Jika Speaking nilai $>60$, nilai reading $>60$, nilai writing $=60$ maka lulus

7) Jika Speaking nilai $>60$, nilai reading $>60$, nilai writing $>60$, nilai listening $<60$ maka tidak lulus

8) Jika Speaking nilai $>60$, nilai reading $>60$, nilai writing $>60$, nilai listening $=60$ maka lulus

9) Jika Speaking nilai $>60$, nilai reading $>60$, nilai writing $>60$, nilai listening $>60$ maka lulus

\section{Kesimpulan}

Berdasarkan hasil analisis dan pembahasan diatas maka, peneliti dapat mengambil kesimpulan bahwa untuk Mata Kuliah Bahasa Inggris Maritim kemampuan berbicara (speaking) mempunyai dampak yang besar terhadap atribut yang lain. Sehingga perlu diberikan perlakuan khusus terhadap taruna yang tidak lulus. Dan perlu peningkatan pembelajaran untuk reading, writing terutama listening.

\section{DAFTAR PUSTAKA}

Afrida, I.R. (2016). Pengembangan Model Penilaian Otentik untuk Mengukur Capaian Pembelajaran Mahasiswa Authentic Assessment Model To Measure Undergraduate Students' Learning Outcomes. Jurnal Biologi dan Pembelajaran Biologi, 1(2), 137-147.

Ardiyansah ,Tri Yuli.(2019). Analysis Of Speaking Assessment In ESP Speaking Class. Journal of English Teaching, Literature, and Applied Linguistics ISSN: 2614-5871 Vol. 3, No. 1; Februari 2019 Published by English Education Department of Universitas Muhammadiyah Gresik. ardi13@umg.ac.id (10 Juni 2021)

International Maritime Organization. (2015). International Maritime Organization Model Course (IMO MC) 3.17 for Maritime English. Cambridge. London.

Larose, Daniel T. (2006). Data mining, Methods and Models. John Wiley \& Son. New Jersey.

Mashlahah, Susi. (2013). Prediksi Kelulusan Mahasiswa Menggunakan Decision Tree dengan Penerapan Algoritma C.45.

Nugraha, Putu Gede Surya Cipta dkk (2016) dalam penelitian yang berjudul Penerapan Metode Decision Tree (Data Mining) Untuk Memprediksi Tingkat Kelulusan Siswa SMPN 1 Kintamani. ISSN Cetak : 2541-2361 | ISSN Online : 2541-3058 Seminar Nasional Vokasi dan Teknologi (SEMNASVOKTEK). Denpasar-Bali, 22 Oktober 2016

Nurgiyantoro, Burhan. (2011). Penelitian Otentik Dalam Pembelajaran Bahasa. Yogyakarta: Gadjah Mada University Press

Panjaitan, Mutiara O. (2010). Penilaian Mata Pelajaran Bahasa Inggris Pusat Kurikulum. Balitbang KemdiknasJurnal Pendidikan dan Kebudayaan, Vol. 16, Nomor 3, Mei 2010.

Rianto, (2010), Metodologi Penelitian Sosial dan Hukum, Jakarta: Granit 
Ridwan, M., Suyono, H., dan Sarosa, M (2013) dalam Penerapan Data Mining Untuk Evaluasi Kinerja Akademik Mahasiswa Menggunakan Algoritma Naive Bayes Classifier.

Selvia Lorena Br.Ginting, Wendi Zarman, Ida Hamidah, (2014), Analisis dan Penerapan Algoritma C4.5 dalam Data Mining untuk Memprediksi Masa Studi Mahasiswa Berdasarkan Data Nilai Akademik, Seminar Nasional Aplikasi Sains dan Teknologi (SNAST), Yogyakarta, 15 November 2014

Sianturi, Fricles Ariwisanto. (2018). Analisa Decision Tree Dalam Pengolahan Data Siswa. Media Informasi Analisa dan Sistem (MEANS) Volume 3 No. 2 Desember 2018.p-ISSN : 2548-6985, e-ISSN : 2599-3089. http://ejournal.ust.ac.id/index.php/Jurnal_Means/ (10 Juni 2021)

Sugiyono. (2014). Metode Penelitian Pendidikan Pendekatan Kuantitatif, Kualitatif, dan R\&D. Bandung: Alfabeta

Swastina,liliana, (2013), Penerapan Algoritma C4.5 untuk Penentuan Prodi Mahasiswa, Jurnal GEMA AKTUALITA, No.1, Vol.2, 93-98

Wahyudin, (2009), Metode Iterative Dischotomizer 3 (ID3) untuk Penyeleksian Penerimaan Mahasiswa Baru, Jurnal Pendidikan Teknologi Informasi dan Komunikasi(PTIK), Vol.1, No.2, $5-15$ 